\title{
Short Term Outcome of Off Pump Coronary Artery Bypass Grafting in Patients with Low Ejection Fraction
}

\author{
MOHAMMAD SERAJUS SALEKIN ${ }^{1}$, MD FAIZUS SAZZAD², SYED AL NAHIAN ${ }^{3}$, \\ SUMSUL ARIF MOHAMMAD MUSA ${ }^{4}$, MOHAMMED RABBIKUL ALAM ${ }^{5}$, \\ DEWAN IFTAKHER RAZA CHOUDHURY ${ }^{6}$, ASIT BARAN ADHIKARY ${ }^{7}$
}

${ }^{1}$ Department of Thoracic surgery, Dhaka Medical College Hospital, Dhaka, ${ }^{2}$ Associate Consultant, Department of Cardiac Surgery, Ibrahim Cardiac Hospital \& Research Institute, Dhaka, ${ }^{3}$ Department of Cardiac Surgery, United Hospital Limited, Dhaka,

${ }^{4}$ Department of Cardiac Surgery, Dhaka Medical College Hospital, Dhaka, ${ }^{5}$ Department of Anesthesiology, National Institute of Cardiovascular Diseases, Dhaka, ${ }^{6}$ Department of Cardiac Surgery, National Heart Foundation Hospital \& Research Institute, Dhaka, ${ }^{7}$ Department of Cardiac Surgery, Bangabandhu Seikh Mujib Medical University, Dhaka.

Address of Correspondence: Md Faizus Sazzad, Associate Consultant Cardiac Surgeon, Ibrahim Cardiac Hospital \& Research Institute, Dhaka.Email:mfsazzad@gmail.com

\begin{abstract}
:
Coronary artery disease is increasing in developing countries. Revascularization surgery in such patients with amenable coronary anatomy is a valid option. Coronary artery bypass grafting in patients with low ejection fraction (EF $<35 \%)$ is very challenging although it is performing successfully in department of Cardiac Surgery of Bangabandhu Sheikh Mujib Medical University now a days. The purpose of this study is to evaluate the safety and effectiveness of off pump coronary artery bypass grafting for EF e" $35 \%$ and EF $<35 \%$ and also to compare between pre and postoperative echocardiographic findings in this two groups. The preoperative, at discharge, 1 month and 3 month postoperative follow up data of total 60 patients in two groups ( EF e"35\% and <35\%) who underwent isolated off pump coronary artery bypass grafting between July 2012 - June 2014 was evaluated.

In group 1 preoperative LVIDd and LVIDs was $54.86 \pm 3.45 \mathrm{~mm}$ and $45.23 \pm 4.13 \mathrm{~mm}$ and LVEF was 42.7 4.66. Postoperatively at 3 month follow up the LVIDd $45.43 \pm 5.03 \mathrm{~mm}$, LVIDs $34.7 \pm 5.33 \mathrm{~mm}$ and LVEF 53.46 \pm 5.06 . The improvement of mean LVIDd and LVIDs is statistically significant $(p<0.001)$ and $(p<0.05)$ respectively. But improvement of $L V E F$ is not statistically significant $(p>0.05)$. Similarly in group 2 patients preoperative LVIDd, LVIDs and LVEF is $67.06 \pm 3.67 \mathrm{~mm}, 59.1 \pm 4.35 \mathrm{~mm}$ and 29.26 \pm 4.25 . Postoperatively at 3 months follow up of this group the LVIDd, LVIDs and LVEF is changed to $57.56 \pm 4.96$ $\mathrm{mm}, 48.3 \pm 5.53 \mathrm{~mm}$ and 38.93 \pm 6.03 . The improvement of mean LVIDd and LVIDs is statistically significant $(p<0.001)$ and $(p<0.05)$ respectively. And the improvement of $L V E F$ is also statistically significant $(p<0.001)$. Significant improvement in terms of CCS grade and NYHA class was also observed specially in $<35 \%$ ejection fraction group at 3 moths follow up.

We concluded that off pump coronary artery bypass grafting can be safely performed to the patients with normal and poor left ventricular ejection. Hence we recommended that off-pump CABG can be safely carry out in case of $<35 \%$ ejection fraction patients.
\end{abstract}

Key Words: Beating Heart Surgery, Coronary artery bypass, Low Ejection Fraction.

University Heart Journal 2018; 14(2): 53-61

Introduction:

Coronary artery disease is the most common cardiovascular disease and it is the major cause of death in the middle aged and older people in the most developing countries. In south Asian region increased prevalence and excess mortality in coronary artery disease is reported by several studies. Moreover this disease starts at young age and more aggressive presentation. Socioeconomic improvement and changes in life style in respect to increased saturated fat intake decrease in physical activity, increasing body weight and consequently increasing rate of Diabetes Mellitus, Dyslipidemia and Hypertension in the population contribute to increase in coronary artery disease. According to the latest WHO data published in April 2011 Coronary Heart Disease Deaths in Bangladesh reached 163,769 or $17.11 \%$ of total deaths. Bangladesh ranks $25^{\text {th }}$ position in the world in respect to cause of death due to coronary artery disease. ${ }^{1}$

Significant morbidity and mortality due to ischemic heart failure is well documented. Revascularization in such patients with amenable coronary anatomy has yielded 
significant functional improvement. ${ }^{2}$ However; left ventricular (LV) dysfunction has been clearly shown to be a predictor of perioperative morbidity and mortality during conventional coronary artery bypass grafting (CABG) on cardiopulmonary bypass (CPB). An analysis from the New York State cardiac surgery data-base including patients who underwent CABG from 1997 to 1999 showed that in-hospital mortality and morbidities were significantly higher in patients with depressed LV function compared with patients with normal LV function. ${ }^{3}$ The use of substantial inotropic and vasopressor support is difficult to quantify but is clearly a frequent and integral component of cardiac surgery in patients with significant LV dysfunction. The use of an intraaortic balloon pump (IABP) is a somewhat more definitive outcome, and in many settings, reflects the next step beyond inotropic support. Crossclamp-induced myocardial ischemia and adverse systemic effects of CPB may produce greater overall physiologic derangement in patients with ventricular dysfunction. Off-pump coronary artery bypass (OPCAB) obviates these factors and may provide a benefit. ${ }^{4}$

Historically, coronary artery bypass grafting $(\mathrm{CABG})$ in patients with LV dysfunction was associated with high perioperative mortality. ${ }^{5}$ However; advances in surgical techniques have led to improved outcomes, making CABG a relatively safe procedure in selected high-risk patients. ${ }^{6}$ The development of specialized techniques, tissue stabilizers and apical suction devices allows the application of off-pump CABG to almost all patients, as surgeon experience matures. Furthermore, there are several reports that off-pump CABG is a safe alternative to on-pump grafting in high-risk patients such as redo CABG cases or those with advanced age, female sex, or impaired LV function. ${ }^{7-9}$

Several prospective nonrandomized studies have supported the assumption that patients with the worst preoperative prognoses would benefit most from a less invasive procedure, avoiding cardiopulmonary bypass and cardioplegic arrest. ${ }^{10}$ The safety of OPCAB techniques in multivessel revascularization has been confirmed in this group of patients. ${ }^{11}$ The purpose of this study is to assess the short term outcome of OPCAB in patients with LV dysfunction.

\section{Rationale:}

Coronary artery bypass grafting $(\mathrm{CABG})$ procedure is usually done by the use of Heart Lung machine that is on pump CABG and also without use of Heart Lung machine that is off pump CABG. As we know using cardiopulmonary bypass bears lots of complications and perioperative morbidities and mortality. And these complications increase several folds in the patients with low ejection fraction. So, doing CABG without using Heart Lung machine will certainly avoid those complications and drawbacks. There is no study has been done in Bangladesh to evaluate outcome, morbidity and mortality in patients with low ejection fraction (EF). The aim of this study is to evaluate short term outcome of off pump coronary artery bypass grafting (OPCAB) in patients with low EF.

\section{Review of literature:}

CABG provides a survival benefit over medical therapy alone in patients with LV dysfunction and coronary artery disease. ${ }^{5,12}$ Alternatives to CABG, such as implantation of LV assist devices and transmyocardial laser revascularization, are restricted; therefore, CABG offers the only feasible chance of improved survival for most patients with severe LV dysfunction. ${ }^{13,14}$ Nevertheless, the out- comes have often been controversial and depend on patient selection, baseline workup, and critical decision- making. ${ }^{15}$

In a systematic review of CABG trials, Nalysnyk and colleagues identified low EF, history of stroke, myocardial infarction, or heart surgery, and the presence of diabetes or hypertension with increased 30-day mortality ${ }^{16}$. OPCAB has gained popularity in recent years, and may improve the outcome in cases of severe LV dysfunction. ${ }^{14}$ Al Ruzzeh and colleagues noted that OPCAB in high-risk patients with multivessel disease had a similar 30-day mortality but fewer major complications than $\mathrm{CABG}^{10}$.

CABG in low EF CAD patients has been reported to be superior to medical therapy by several authors. Alderman showed that patients with an $\mathrm{EF}<35 \%$ who were treated with medical management had a $43 \% 5$-years survival rate compared with $63 \% 5$ year survival rate in the surgically treated patients. ${ }^{5}$ Passamani followed a group of CABG patients with an $\mathrm{EF}<50 \%$ for 7 years and showed that $84 \%$ of the surgically treated patients were alive at 7 years, whereas only $70 \%$ of medically treated patients were alive. ${ }^{17,5}$ There has been increasing interest in off-pump CABG because it is thought to be less invasive than conventional CABG using $\mathrm{CPB}$ and cardioplegic arrest. Cardiopulmonary bypass causes a systemic inflammatory reaction that may result in morbidity after cardiac surgery. In a multicenter study on 2,108 patients from 24 US institutions, Roach and colleagues concluded that adverse cerebral outcomes 
after conventional $\mathrm{CABG}$ are relatively common and serious; they are associated with substantial increases in mortality, length of hospitalization and use of intermediate or long-term care facilities. ${ }^{18}$

Some studies found that off-pump CABG for patients with LV impairment was associated with surgical outcomes similar to those with normal LV function, and others noted that certain high-risk groups may be better treated with off-pump CABG. ${ }^{19}$ Patients also experience marked functional improvement; in one report, $89 \%$ of patients were in New York Heart Association functional class III or IV preoperatively, and $79 \%$ were in class I or II at 50 months postoperatively. ${ }^{20}$ Even at the extreme end of the LV dysfunction spectrum, (EF 10\%-20\%, mean 18\%), patients can be operated on safely with reasonable mortality $(11 \%)$, and also derive long-term myocardial functional benefit with a mean EF of $35 \%$ at 1 -year follow-up. ${ }^{21}$

Furthermore, those with significant LV dysfunction often have some degree of other organ dysfunction, especially liver and kidney, and thus may be more susceptible to exacerbation of such dysfunction by CPB. A retrospective comparison of on- and off-pump approaches in patients with LV dysfunction observed IABP rates of $14.7 \%$ vs. $7.5 \%$, and mortality of $14.1 \%$ vs. $6.6 \%{ }^{10}$. Another retrospective study of patients with LV dysfunction found hospital mortality of $10.9 \%$ for $\mathrm{CABG}$ on $\mathrm{CPB}$ and $3 \%$ for OPCAB ${ }^{8} \mathrm{~A}^{\mathrm{A}}$ prospective registry of 48 patients with $\mathrm{LV}$ dysfunction undergoing OPCAB noted IABP use in $25 \%$ and a perioperative mortality rate of $7 \% .{ }^{9}$ These studies suggest a benefit in employing OPCAB techniques.

Over past decades, 30 days operative mortality rates for CABG only procedures have significantly declined. In spite of a significant increase in the preoperative risk in the patients, this indicates a very significant improvement in the quality of cardiac surgical care rendered by The Society of Thoracic Surgeons (STS) members ${ }^{22}$. It is clearly recognized that complication in cardiac surgery may not be fatal but can significantly impact on patient's functional status and quality of life. The ability of CABG surgery to improve overall health related quality of life has been demonstrated and is considered as a major indication for a CABG operation. ${ }^{23}$

\section{Materials \& Methods:}

This study was conducted in the Department of Cardiac Surgery, Bangabandhu Seikh Mujib Medical University, Dhaka. Study period was from July 2012 - June 2014. It was a Prospective Cohort Study. The study was carried out in patients with Ischemic Heart Disease (IHD) who underwent isolated off pump coronary artery bypass graft surgery. Total number of patients was 60 (Sixty). Sampling was Purposive.

\section{Patients were divided in Two Groups.}

Group 1: 30 (Thirty) patients with Ejection Fraction (EF) $\geq 35 \%$

Group 2: 30(Thirty) patients with Ejection Fraction (EF) $<35 \%$

Inclusion criteria: Only IHD patients with EF below 35\% and above 35\% who undergo elective Off Pump CABG. Exclusion criteria: i) Patients undergo combined CABG and valvular or congenital cardiac procedures. ii) Systemic disease such as end stage renal disease, hepatic failure, respiratory failure. iii) Previous history of cardiac surgery. iv) Emergency CABG. v) Redo CABG.

\section{Measures of variables:}

Following variables have been measured in the study

Pre-operative variables:

a. Demographic Data: i) Age, ii) Sex, iii) Height, iv)Weight, v) Body surface area (BSA).

Risk Factors: Sedentary life style, Hypertension, Smoking, Diabetes mellitus, Positive family history, Hypercholesterolemia.

b. History and clinical examination: Careful history regarding the complaints and functional disability in terms of New York Heart Association (NYHA) class and Canadian Cardiology Society (CCS) angina class will be done.

c. Investigations: i) FBS, ii) Serum Creatinine, iii) Chest X ray, iv) Electrocardiography (ECG) v) Echocardiography: 1. Left ventricular end diastolic diameter (LVIDd), 2. Left ventricular end systolic diameter (LVIDs), 3. Ejection Fraction (EF\%) and vi) Coronary Angiogram (CAG)

Per operative variables: a. No. of grafts, b. Total operation time

Post-operative variables: a. Ventilation time in hour, b. Inotropic support

Dopamine $(\mu \mathrm{gm} / \mathrm{hr})$, Adrinaline $(\mu \mathrm{gm} / \mathrm{hr})$, Dobutamine $(\mu \mathrm{gm} / \mathrm{hr})$, Isoprenaline $(\mu \mathrm{gm} / \mathrm{hr})$, Milrinone $(\mu \mathrm{gm} / \mathrm{hr}), \mathrm{c}$. Blood gas analysis, d. Length of ICU stay, e. Total chest drainage (ml), f. Length of hospital stay, g. Reoperation 
for bleeding, h. Sternal wound infection, i. Hospital mortality and $\mathrm{j}$. Echocardiography

\section{Study Procedure:}

The permission from the institutional review board and informed and written consent was taken from all patients for this study. Patients admitted for off pump coronary artery bypass grafting that fulfills the selection criteria was enrolled in the study. Cases were selected purposively. Detailed history, clinical examination and relevant investigation reports of all patients were recorded in the data collection sheet preoperatively. All patients were premedicated with tablet midazolam 7.5 mg per oral the night before surgery. Morphine sulphate $(0.1 \mathrm{mg} / \mathrm{kg})$ intramuscularly (I.M.) and tablet Metoprolol $50 \mathrm{mg}$ orally will be given 60 minutes before the operation. Patients were taken to the operating room, oxygenation will be done by face mask with $50 \%$ oxygen. Peripheral venous catheterization and central venous catheterization in the internal jugular vein was performed with all aseptic precautions. Standard anesthetic technique including induction, maintenance and weaning /recovery were followed for the both procedure. Both the group was operated by same surgical team. A median sternotomy was done and at the same time Great saphenous vein was harvested and prepared for graft. Internal mammary artery was prepared for the pedicle graft. The distal anastomosis of reverse saphenous venous graft was done with cross clamp. Echocardiography was done to determine Ejection Fraction (EF \%) by modified Simpson's method using two dimensional (2D), M mode and color Doppler echocardiography pre operatively, at the time of discharge from hospital, 1 month and 3 months after surgery. All data was collected and recorded in data collection sheet. Data editing and analysis was done. Data and results will be presented in the form of tables and diagram where applicable. Statistical analysis was conducted on SPSS (Statistical package for the social sciences) latest version as per availability for windows software. Sensitivity, specificity and data accuracy was calculated. Parametric data was expressed in mean $\pm \mathrm{SD}$. Test of significance was done and level of significance will be defined as $p$ value $<0.05$. The difference of LVEF between $<35 \%$ and $\geq 35 \%$ ejection fraction patients was compared by unpaired t-test. The pre and postoperative difference of LVIDd and LVIDs between $<35 \%$ and $\geq 35 \%$ ejection fraction patients was compared by paired t-test. The mean \pm SD LVEF between pre and post operative was compared by paired t-test. Pre operative, discharge and $1^{\text {st }}$ month and $3^{\text {rd }}$ month follow up LVIDd, LVIDs and EF were data were compared by ANOVA test.

\section{Results and Observations:}

Total number of 60 patients were selected for off pump coronary artery bypass surgery. Among them 30 patients ejection fraction was $\geq 35 \%$ (Group1) and 30 patients ejection fraction was $<35 \%$ (Group 2). The findings of the study obtained from data analysis are presented below.

Age distribution: Table 1. shows that among Group1 patients, highest number of percentage $60 \%$ were in 41 50 years age group and both 51-60 and 61-70 years age group percentage were equal that is $20 \%$. Whereas among Group 2 patients highest percentage were in 61-70 years age group and both 41-50 and 51-60 age group patients were $9 \%$.

Table-I

Age distribution of the patients.

\begin{tabular}{lcc}
\hline Age of the Patients (years) & $\begin{array}{c}\text { Group 1 } \\
\mathrm{n} \mathrm{( \% )}\end{array}$ & $\begin{array}{c}\text { Group 2 } \\
\mathrm{n}(\%)\end{array}$ \\
\hline $41-50$ & $18(60)$ & $9(30)$ \\
$51-60$ & $6(20)$ & $9(30)$ \\
$61-70$ & $6(20)$ & $12(40)$ \\
Total & $30(100)$ & $30(100)$ \\
Mean age (years) & $51.9 \pm 8.69$ & $57.2 \pm 7.48$ \\
\hline
\end{tabular}

Figures in Parenthesis denote corresponding \%, Data were presented as mean $\pm \mathrm{SD}$

In Group 1 patients and in Group2 patients male patient was 24 and 25 respectively and female patient was 6 and 5 respectively. The mean height was $157.96 \pm 3.65 \mathrm{~cm}$ in group 1 patients and $158.96 \pm 4.21 \mathrm{~cm}$ in group 2 patients. The mean weight was $69.8 \pm 4.67 \mathrm{~kg}$ in group1 patients and $71.63 \pm 4.08 \mathrm{~kg}$ in group 2 patients. The mean body surface area was $1.74 \pm 0.12 \mathrm{~m}^{2}$ in group 1 patients and $1.75 \pm 0.05 \mathrm{~m}^{2}$ in group 2 patients. The mean difference of height $(\mathrm{cm})$, weight $(\mathrm{kg})$ and body surface area $\left(\mathrm{m}^{2}\right)$ were statistically insignificant $(\mathrm{p}>0.05)$ in unpaired $t$ test.

All the patients had some risk factors for coronary artery disease (CAD). Group 1 patients out of 30 patients 19 (63.3\%) were smoker, 12(40\%) had Diabetes Mellitus, $11(36.66 \%)$ had hypertension and $7(23.33 \%)$ had hyperlipidaemia. On the other hand in group 2 patients 25(83.3\%) were smoker, 17 (56.67\%) had Diabetes Mellitus, 14 (46.66\%) had hypertension and 8(26.66\%) had hyperlipidaemia.

Table 2 depicts the comparison between preoperative and postoperative during 1 month and 3 months in CCS grade and NYHA class in the study groups. The table shows 
that the preoperative CCS grade I, II, III and IV occupied $1,12,15$ and 2 patients respectively in group 1 patients. Whereas CCS grade II, III and IV occupied 8, 18 and 4 patients respectively in group 2 patients. None in CCS grade I. During postoperative follow up in 1 month CCS grade I, II and III occupied 17, 12 and 1 patient respectively in grouplpatients. On the other hand in 1 month postoperative follow up of CCS grade I, II and III occupied 11, 16 and 3 patients. No patient was in CCS grade IV in both groups. In 3 months postoperative follow up of CCS grade I and II occupied 22 and 6 respectively in group 1 patient. While CCS grade I, II and III occupied 20, 9 and 1 patients in 3 months follow up in group 2 patients. None was in grade III and IV in group 1 patients and none in grade IV in group 2 patients.

The table 2 also shows the changes in NYHA class in group 1 patients group and in group 2 patients. Preoperatively NYHA class I, II, III and IV occupied 1, 17,10 and 2 patients in group 1 respectively. On the other hand in group 2 NYHA class II, III and IV occupied 18, 8 and 4 patients respectively with no patient in class I. In 1 month post-operative follow up in group 1 NYHA class I, II and III occupied 12, 13 and 5 patients respectively. No patient in class I. where as in group 2;1 month postoperative follow up shows NYHA class I, II, III and IV occupied 14, 12, 3 and 1 patients respectively. During 3 months post-operative follow up of group 1 patients, NYHA class I and II occupied 25 and 3 patients respectively with no patient in III and IV class. While in group 2 NYHA class I and II occupied only 25 and 5 patients respectively. None was in class III and IV.
Among the investigation, Xray chest in group 1 highest number, that is $18(60 \%)$ patients was in no abnormality followed by $4(13.33 \%)$ in enlarge cardiac silhouette and 4 $(13.33 \%)$ in hilar vessels prominence and upper lobe diversion findings. Both no specific findings and hilar vessels prominence findings had equal that is $2(66 \%)$ number of patients. Where as in group 2 no abnormality findings also had highest that is $19(63.33 \%)$ patients followed by $2(6.66 \%)$ each in hilar vessels prominence and in hilar vessels prominence and upper lobe diversion findings. Only $1(3.33 \%)$ patient was in no specific findings.

The ECG in group1, $12(40 \%)$ patients were in no abnormality followed by $8(26.66 \%)$ in evidence of old inferior MI, $6(20 \%)$ in evidence of old antero-inferior MI and $4(13.33 \%)$ in no specific findings. On the other hand in group 2, $13(43.33 \%)$ patients were in no abnormality followed by $7(23.33 \%)$ in old inferior MI, $7(23.33 \%)$ in old antero-inferiorMI and only $3(10 \%)$ in no specific findings.

The distribution of the involvement of coronary arteries among the patients of Group 1 and 2 was: In Group 1 patients 2 patients had single vessel coronary disease, 7 patients had double vessels coronary disease and 21 patients had triple vessels disease. On the other hand in Group 2 patients 6 patients had double vessels disease and 24 patients had triple vessels coronary disease. No one had single vessel disease.

Echocardiography findings in preoperative and postoperative (during discharge, 1 month follow up, 3 month follow up) are shown in table 3.

Table-II

Preoperative and postoperative NYHA and CCS functional Class

\begin{tabular}{|c|c|c|c|c|c|c|}
\hline & \multirow{2}{*}{\multicolumn{2}{|c|}{$\begin{array}{l}\text { Preoperative } \\
(n=60)\end{array}$}} & \multicolumn{4}{|c|}{ Post Operative } \\
\hline & & & \multicolumn{2}{|c|}{1 month $(\mathrm{n}=60)$} & \multicolumn{2}{|c|}{3 month $(\mathrm{n}=60)$} \\
\hline & $\begin{array}{c}\text { Group } 1 \\
\mathrm{n}(\%)\end{array}$ & $\begin{array}{c}\text { Group2 } \\
\mathrm{n}(\%)\end{array}$ & $\begin{array}{l}\text { Group } 1 \\
\mathrm{n}(\%)\end{array}$ & $\begin{array}{c}\text { Group2 } \\
\mathrm{n}(\%)\end{array}$ & $\begin{array}{c}\text { Group1 } \\
\mathrm{n}(\%)\end{array}$ & $\begin{array}{c}\text { Group2 } \\
\mathrm{n}(\%)\end{array}$ \\
\hline \multicolumn{7}{|l|}{$\overline{\mathrm{CCS} \text { grade }}$} \\
\hline GradeI & $1(3.33)$ & $0(0)$ & $17(56.6)$ & $11(36.6)$ & $22(73.3)$ & $20(66.6)$ \\
\hline Grade II & $12(40)$ & $8(26.6)$ & $12(40)$ & $16(53.3)$ & $6(20)$ & $9(30)$ \\
\hline GradeIII & $15(50)$ & $18(60)$ & $1(3.33)$ & $3(10)$ & $0(0)$ & $1(3.33)$ \\
\hline GradeIV & $2(6.66)$ & $4(13.3)$ & $0(0)$ & $0(0)$ & $0(0)$ & $0(0)$ \\
\hline Total & 30 & 30 & 30 & 30 & 28 & 30 \\
\hline \multicolumn{7}{|l|}{ NYHA } \\
\hline ClassI & $1(3.33)$ & $0(0)$ & $12(40)$ & $14(46.6)$ & $25(83.3)$ & $25(83.3)$ \\
\hline ClassII & $17(56.6)$ & $18(60)$ & $13(43.3)$ & $12(40)$ & $3(10)$ & $5(16.6)$ \\
\hline ClassIII & $10(33.3)$ & $8(26.6)$ & $5(16.6)$ & $3(10)$ & $0(0)$ & $0(0)$ \\
\hline ClassIV & $2(6.66)$ & $4(13.3)$ & $0(0)$ & $1(3.33)$ & $0(0)$ & $0(0)$ \\
\hline Total & 30 & 30 & 30 & 30 & 28 & 30 \\
\hline
\end{tabular}

$\mathrm{n}$ denote number of sample, figures in the parentheses denote corresponding $\%$ 
Table-III

Changes in Echocardigraphic findings in the groups.

\begin{tabular}{lccccc}
\hline Findings & Preoperative & At discharge & $\begin{array}{c}\text { 1 month } \\
\text { after operation }\end{array}$ & $\begin{array}{c}\text { 3 month } \\
\text { after operation }\end{array}$ & P value \\
\hline LVIDd (mm) & $54.86 \pm 3.45$ & $57.56 \pm 4.07$ & $50.2 \pm 4.18$ & $45.43 \pm 5.03$ & $<0.05 \mathrm{~S}$ \\
LIVDs (mm) & $45.23 \pm 4.13$ & $47.03 \pm 4.46$ & $40.53 \pm 4.83$ & $35.7 \pm 5.33$ & $<0.05^{\mathrm{S}}$ \\
LVEF (\%) & $42.7 \pm 4.66$ & $41.66 \pm 4.71$ & $45.6 \pm 4.66$ & $50.46 \pm 5.06$ & $<0.001 \mathrm{~S}^{\text {Group } 1}$ \\
Group 2 & $67.06 \pm 3.67$ & $68.1 \pm 3.39$ & $61.13 \pm 5.45$ & $57.56 \pm 4.96$ & $<0.05^{\mathrm{S}}$ \\
LVIDd(mm) & $59.1 \pm 4.35$ & $60.53 \pm 4.44$ & $53.83 \pm 6.34$ & $48.3 \pm 5.53$ & $<0.05 \mathrm{~S}$ \\
LIVDs (mm) & $29.26 \pm 4.25$ & $28.63 \pm 4.01$ & $32.8 \pm 5.56$ & $35.93 \pm 6.03$ & $<0.05 \mathrm{~S}$ \\
LVEF $(\%)$ &
\end{tabular}

$\mathrm{S}$ - Significant, data were presented as mean $\pm \mathrm{SD}$, Data were analyzed using ANOVA test, $\mathrm{p}-$ value $<0.05$ considered significant

It was found that in group 1 the mean \pm SD LVIDd was $54.86 \pm 3.45 \mathrm{~mm}$ during preoperative period and it was $57.56 \pm 4.07 \mathrm{~mm}$ during discharge. During 1 month postoperative follow up LVIDd was $50.2 \pm 4.18 \mathrm{~mm}$ and during 3 month follow up it was $45.43 \pm 5.03 \mathrm{~mm}$. In ANOVA test preoperative, discharge, 1 month and 3 month follow up LVIDd was statistically significant $(<0.05)$.

Similarly it was observed that in group 2 the mean \pm SD LVIDs was $45.23 \pm 4.13 \mathrm{~mm}$ during preoperative period and it was $48.03 \pm 4.46 \mathrm{~mm}$ during discharge. During 1 month postoperative follow up LVIDs was $40.53 \pm 4.83 \mathrm{~mm}$ and during 3 month follow up it was $34.7 \pm 5.33 \mathrm{~mm}$. In ANOVA test preoperative, discharge, 1 month and 3 month follow up LVIDs was statistically significant $(<0.05)$.

We found that in group 1 the mean \pm SD LVEF was $42.7 \pm 4.66(\%)$ during preoperative period and it was $39.66 \pm 4.71(\%)$ during discharge. During 1 month postoperative follow up LVEF was $48.6 \pm 4.66(\%)$ and during 3 month follow up it was 53.46 $\pm 5.06(\%)$. In ANOVA test preoperative, discharge, 1 month and 3 month follow up LVEF was statistically significant $(<0.001)$.

On the other hand in group 2 it was evident that the mean \pm SD LVIDd in preoperative period was $67.06 \pm 3.67$ $\mathrm{mm}$ and duringdischarge it was $68.1 \pm 3.39 \mathrm{~mm}$. and during 1month follow up the LVIDd was $61.13 \pm 5.45 \mathrm{~mm}$ and during 3 month follow up it was $57.56 \pm 4.96 \mathrm{~mm}$. in ANOVA test the preoperative, discharge, 1 month and 3 month follow up of LVIDd was statistically significant $(<0.05)$.

It was found that in group 1 the mean \pm SD LVIDs in preoperative period was $59.1 \pm 4.35 \mathrm{~mm}$ and during discharge it was $60.53 \pm 4.44 \mathrm{~mm}$. and during 1month follow up the LVIDs was $52.83 \pm 6.34 \mathrm{~mm}$ and during 3 month follow up it was $48.3 \pm 5.53 \mathrm{~mm}$. in ANOVA test the preoperative, discharge, 1 month and 3 month follow up of LVIDs was statistically significant $(<0.05)$.

Similarly it was found that in group 2 the mean \pm SD LVEF in preoperative period was $29.26 \pm 4.25(\%)$ and during discharge it was $27.63 \pm 4.01(\%)$ and during 1 month follow up the LVEF was $34.8 \pm 5.56(\%)$ and during 3 month follow up it was $38.93 \pm 6.03(\%)$ in ANOVA test the preoperative, discharge, 1 month and 3 month follow up of LVEF was statistically significant $(<0.001)$.

The change in preoperative and post-operative 3 month follow up of LVIdd in group 1 was statistically significant $(<0.001)$ in paired t-test. While, the change in preoperative and postoperative 3 month follow up of LVIds in group 2 was statistically significant $(<0.05)$ in paired t-test. It was also found that the change in preoperative and postoperative 3 month follow up of LVEF in group 1 was not statistically significant $(0.123)$ in paired t-test.

On the other hand The change in preoperative and postoperative 3 month follow up of LVIdd in group 2 was statistically significant $(<0.001)$ in paired t-test. While the change in preoperative and postoperative 3 month follow up of LVIds in group 1 was statistically significant $(<0.05)$ in paired t-test. It was also found that the change in preoperative and postoperative 3 month follow up of LVEF in group 1 was statistically significant $(<0.001)$ in paired t-test. LVEF between the group 1 and 2 in paired t-test it was statistically significant $(<0.001)$ at 3 months; which was $35.93 \pm 6.03$ in Group 1 vs $50.46 \pm 5.06$ in Group 2. 
The postoperative outcome parameters like the mean duration of mechanical ventilation in group 1 and group 2 was $7.55 \pm 2.03$ hours and $12.76 \pm 5.36$ hours respectively. And the difference was statistically in significant $(p>0.05)$ in unpaired t-test. Whereas, the mean duration of ICU stay between group 1 and 2 was $30.85 \pm 7.44$ hours and $32.36 \pm 7.31$ hours respectively. The difference between this two group was statistically significant $(<0.001)$ in unpaired t-test. The last postoperative parameter was total hospital stay. The mean duration of total hospital stay in both groups was 7.7 \pm 1.2 days and $8.5 \pm 1.98$ days respectively. This difference between this two group was statistically significant $(<0.05)$ in unpaired t-test.

Among the major postoperative complications 2 cases of prolonged ventilation $>24$ hours was found in group 2. Whereas deep sternal wound infection was found 1 case each in both the groups. None was found in other complications like stroke, renal dysfunction and reoperation in both the groups.

\section{Discussion:}

Bangabandhu Sheikh Mujib Medical University is the only medical university in Bangladesh and the department of Cardiac Surgery of Bangabandhu Sheikh Mujib Medical University started its journey in 2004. Since then it has become the leading cardiac surgery center of Bangladesh. This study was conducted in the department of cardiac surgery of Bangabandhu Sheikh Mujib Medical University from July 2012 - June 2014. All the surgery was performed by the same surgical team. Total number of patients was 60 , which was divided into two groups, 30 patients in each group.

Male predominance in this study has been seen in both the groups which is $<84 \%$ and this findings are similar to the study conducted by Meharwal and colleagues which was which is $90.4 \% .^{7}$ According to the age distribution highest number of patients was in 61-70 years group in both in group 1 and group 2. Study conducted by Daniel J. Goldstein and colleagues also found highest number of patients belonging to 61-70 years age group ${ }^{8}$. The study risk factors showed majority of the patients were smoker. They also had other risk factors like Diabetes Mellitus, hypertension and hyperlipidemia. The mean height in group 1 was $158.96 \pm 4.21(\mathrm{~cm})$ and in group 2 was $157.7 \pm 3.65(\mathrm{~cm})$. The mean weight in group 1 was $71.63 \pm 4.08(\mathrm{~kg})$ and in group 2 was $69.8 \pm 4.67(\mathrm{~kg})$. The mean body surface area was in group $1,1.75 \pm 0.05\left(\mathrm{~m}^{2}\right)$ and in group 2 was $1.74 \pm 0.12\left(\mathrm{~m}^{2}\right)$. Though these observations were statistically insignificant $(\mathrm{p}>0.05)$.
All the patients were symptomatic with pain. This is similar to most of the studies. ${ }^{3,13}$ Most of the patients were in Canadian Cardiology Society grade III. In both groups $15(50 \%)$ in group 1 and $18(60 \%)$ in group 2 were found. Apart from pain all were symptomatic with exertional dyspnea with most were of New York Heart Association class II. In group 1 it was 17 (56.6\%) and in group 2 it was $18(60 \%)$. Class III and IV had $10(33.3 \%)$ and $2(6.66 \%)$ in group 1 and $8(26 \%)$ and $4(13 \%)$ in group 2 respectively. Preoperatively most of the patients were in class II and III in both group which is not consistent with study conducted by Islamoglu F. and his colleagues. $^{20}$

Postoperatively at 3 months follow up most of the patients became class I which is $25(83 \%)$ in each group. These findings are similar to the findings of the study conducted by Islamoglu F. and his colleagues ${ }^{20}$. Chest X-ray was done preoperatively in every patient. Most of them had no abnormality with $60 \%$ and $63.33 \%$ in group 1 and group 2 respectively. Enlarged cardiac silhouette in transverse diameter was found in $13.3 \%$ and $20 \%$ in group 1 and 2 respectively. As the patients were controlled medically well, hilar vessel prominences only in $6.66 \%$ in each group.

Electrocardiography was done preoperatively in every patient. Most of them had no abnormality, which was $40 \%$ and $43.33 \%$ in group 1 and group 2 respectively. $26.66 \%$ and $23.33 \%$ had evidence of old inferior myocardial infarction in group 1and group 2 respectively. While $20 \%$ and $23.33 \%$ patients had evidence of old antero-inferior myocardial infarction in group 1 and group 2 respectively.

Echocardiography was done preoperatively, during discharge and postoperative 1 month and 3 month follow up using modified Simpson's biplane method. Those parameters findings are given in table. The mean \pm SD left ventricular internal diameter in diastole (LVIDd) and left ventricular internal diameter in systole (LVIDs) and left ventricular ejection fraction (LVEF) in pre and postoperatively 3 months shown for both groups. For in group 1 patients preoperative LVIDd and LVIDs was $54.86 \pm 3.45 \mathrm{~mm}$ and $45.23 \pm 4.13 \mathrm{~mm}$ respectively. LVEF for this group is $42.7 \pm 4.66$ (\%). Postoperatively at 3 month follow up in this group of patients is LVIDd $45.43 \pm 5.03 \mathrm{~mm}$, LVIDs $34.7 \pm 5.33 \mathrm{~mm}$ and LVEF $53.46 \pm 5.06(\%)$. The improvement of mean LVIDd and LVIDs is statistically significant $(\mathrm{p}<0.001)$ and $(\mathrm{p}<0.05)$ respectively. But improvement of LVEF is not statistically significant $(\mathrm{p}>0.05)$. 
Similarly in group 2 patients preoperative LVIDd, LVIDs and LVEF is $67.06 \pm 3.67 \mathrm{~mm}, 59.1 \pm 4.35 \mathrm{~mm}$ and $29.26 \pm 4.25(\%)$ respectively. Postoperatively at 3 months follow up of this group the LVIDd, LVIDs and LVEF is changed to $57.56 \pm 4.96 \mathrm{~mm}, 48.3 \pm 5.53 \mathrm{~mm}$ and $38.93 \pm 6.03(\%)$ respectively. The improvement of mean LVIDd and LVIDs is statistically significant $(p<0.001)$ and $(p<0.05)$ respectively. And the improvement of LVEF is also statistically significant $(\mathrm{p}<0.001)$. These findings are mostly consistent with the findings of other studies conducted by Trachiotis G D and his colleagues and Islamgolu $\mathrm{F}$ and his colleagues ${ }^{13,20}$.

Postoperative ICU stay was measured in hours. The mean \pm SD ICU stay for group 1 patients was $30.85 \pm 7.44$ hours and for group 2 patients it was $32.36 \pm 7.31$ hours, comparison of this findings was statistically significant $(p<0.001)$. But comparison of duration of mechanical ventilation and total hospital stay between these two groups were not statistically significant.

The mortality was found in only in each group was 1 in number. Morbidity was observed in prolonged ventilation in group 2. And equal number of case found in wound infection in each group. This above findings were consistent with studies conducted by Ascione R. and his colleagues and Lslamoglu F and his colleagues ${ }^{15,20}$.

\section{Conclusion:}

In this series of patients with left ventricular dysfunction, off pump CABG was carried out with good early outcome with low mortality and morbidity and significant improvement in postoperative left ventricular function.

Post operative morbidity like arrhythmia, neurological manifestation, renal failure, reoperation did not take place , but only a single case of wound infection was found in each group. Mortality was encountered in normal ejection fraction group. No mortality was found in $<35 \%$ ejection fraction group. CCS grade and NYHA functional class improved from preoperative period to postoperative 3 months follow up.

It can be concluded that off pump coronary artery bypass grafting can be safely performed to the patients with normal and poor left ventricular ejection. However poor ejection fraction patients show somewhat better result regarding mortality and morbidity. From this study it can be concluded that off pump coronary artery bypass grafting can be performed safely and effectively for $<35 \%$ ejection fraction patients which helps to improve patients quality of life in terms of CCS grade, NYHA class and echocardiographic findings of left ventricular status.

\section{References:}

1. World health rankings, live longer live better [internet].2012 [cited 2012 Nov 10]. Available from: http://www.worldlifeexpectency.com/ country-health-profile/bangladesh

2. Elefteriades JA, Morales DL, Gradel C, Tollis G Jr, Levi E, Zaret BL. Results of coronary artery bypass grafting by a single surgeon in patients with left ventricular ejection fractions $<$ or $=30 \%$. Am J Cardiol 1997;79:1573-78.

3. Topkara VK, Cheema FH, Kesavaramanujam S, Coronary artery bypass grafting in patients with low ejection fraction. Circulation 2005;112(9 Suppl):I-344-50.

4. Woo YJ, Grand TJ, Liao GP, Panlilio CM. Off-pump revascularizatrion for significant left ventricular dysfunction. Asian Cardiaovasc Thorac Ann 2006; 14:306-9.

5. Alderman EL, Fisher LD, Litwin P, Kaiser GC, Myers WO, Maynard $\mathrm{C}$, et al. Results of coronary artery surgery in patients with poor left ventricular function (CASS). Circulation 1983;68:785-95

6. Christakis GT, Weisel RD, Fremes SE, Ivanov J, David TE, Goldman $\mathrm{BS}$, et al. Coronary artery bypass grafting in patients with poor ventricular function. Cardiovascular surgeons of the University of Toronto. J Thorac Cardiovasc Surg 1992; 103: 1083-92

7. Meharwal ZS, Trehan N. Off pump coronary artery bypass grafting in patients with left ventricular dysfunction. Heart Surg Forum 2002;5:41-45.

8. Goldstein DJ, Beauford RB, Luk B, Karanam R, Prendergest T, Sardari F, et al. Multivessel off pump revascularization in patients with severe left ventricular dysfunction. Eur J Cardiothorac Surg 2003;24:72-80.

9. Eryilmaz S, Corapcioglu T, Eren NT, Yazicioglu L, Kaya K, Akalin H. off pump coronary artery bypass in the left ventricular dysfunction. Eur J Cardiothorac Surg 2002;21:36-40.

10. Al - Ruzzeh S, Nakamura K, Athanasiou T, Modine T, George S, Yacoub M, et al. Does off pump coronary artery bypass surgery $(\mathrm{OPCAB})$ improve the outcome in high risk patients? A comparative study of 1398 high risk patients. Eur J Cardiothorac Surg 2003; 23:50-55.

11. Arom KV, Flavin TF, Emery RW, Kshettry VR, Petersen RJ, Janey PA. Is low ejection fraction safe for off pump coronary bypass operation? Ann Thorac Surg 2000; 70: 1021-25.

12. Pigott JD, Kouchoukos NT, Oberman A, Cutter GR. Late results of surgical and medical therapy for the patients with coronary artery disease and depressed left ventricular function. LAm Coll Cardiol. 1985;5:1036-45

13. Trachiotis GD, Weintraub WS, Johnston TS, Jones EL, Guyton RA, Carver JM. Coronary artery bypass grafting in patients with advanced left ventricular dysfunction. Ann Thorac Surg 1998;66:1632-39

14. Nishi H, Miyamoto S, Takanashi S, Minamimura H, Ishikawa T, Shimizu Y. Complete revascularization in patients with severe left ventricular dysfunction. Ann Thorac Cardiovasc Surg 2003;9: $111-16$

15. Ascione R. Severe left ventricular dysfunction : a continuous surgical challenge. J Card Surg 2006;21:233-34 
16. Nalysnyk L, Fahrbach K, Reynolds MW, Zhao SZ, Ross S. Adverse events in coronary artery bypass graft $(\mathrm{CABG})$ trials: a systemic review and analysis. Heart 2003;89:767-72

17. Passamani F, Davis KR, Gillespie ML, Killin T. A randomized trial of coronary artery bypass surgery of patients with low ejection fraction. N Engl J Med. 1985;312:1665-71

18. Roach GW, Kanchuger M, Mangano CM, Newman M, Nussmeier $\mathrm{N}$, Wolman R et al. Adverse cerebral outcomes after coronary bypass surgery. Multicenter study of perioperative ischemia research group and the ischemia research and education foundation investigators. N Engl J Med 1996;335:1857-63

19. Hart JC, Puskas JD, Sabik JF, $3^{\text {rd }}$. Off pump coronary revascularization : current state of the art. Semin Thorac Cardiovasc Surg 2002;14:70-81
20. Lslamoglu F, Apaydin AZ, Posacioglu H, Ozbaran M, Hamalu A, Buket $\mathrm{S}$, et al. Coronary artery bypass grafting in patients with poor left ventricular function. Jpn Heart J 2002;43:343-56

21. Carr JA, Haithcock BE, Paone G, Barnabei AF, Silverman NA. longterm outcome after coronary artery bypass grafting in patients with severe left ventricular dysfunction. Ann Thorac Surg 2002;74:1531-36

22. Ferguson TB, Jr, Hammil BG, DeLong ER, et al., A decade of change : risk profiles and outcomes for isolated CABG procedures, 19901999, ANN Thorac Surg 2002;73:480-90

23. Rumsfeld JS, Magid D, O'Brian MM,et al., Changes in health related quality of life following coronary artery bypass graft surgery, Ann Thorac Surg 2001;72:2026-32 